\title{
ON CHAOTIC ORDER OF TWO OPERATORS ON HILBERT SPACE
}

\author{
C.-S. LIN
}

Abstract. In this article we characterize an inequality resulted from the chaotic order of two operators on a Hilbert space in terms of Heinz-Kato-Furuta-type inequalities. Consequently, some new characterizations of the weaker version for the Löwner-Heinz inequality are obtained. Finally we introduce the notion of high-order Cauchy-Schwarz inequalities, and its applications are given.

Mathematics subject classification (2000): 47A63, 47A62.

Key words and phrases: Polar decomposition of operator, chaotic order of two operators, Furuta's inequality, Löwner-Heinz inequality, high-order Cauchy-Schwarz inequalities.

\section{REFERENCES}

[1] T. ANDO, On some operator inequalities, Math. Ann., 279 (1987), 157-159.

[2] T. FURUTA, A simplified proof of Heinz inequality and scrutiny of its equality, Proc. Amer. Math. Soc., 97 (1986), 751-753.

[3] T. FuRUTA, $A \geqslant B \geqslant O$ assures $\left(B^{r} A^{p} B^{r}\right)^{1 / q} \geqslant B^{(p+2 r) / q}$ for $r \geqslant 0, p \geqslant 0, q \geqslant 1$ with $(1+2 r) q \geqslant p+2 r$, Proc. Amer. Math. Soc., 101 (1987), 85-88.

[4] M. FUJII, T. FURUTA AND E. KAMEI, Furuta's inequality and its application to Ando's theorem, Lin. Alge. Appl., 179 (1993), 161-169.

[5] M. FuJII, Around the Furuta inequality, preprint.

[6] M. G. FuJII, E. KAMEI, C. KotANI AND H. YAMADA, Furuta's determinant type generalizations of Heinz-Kato inequality, Math. Japon., 40 (1994), 259-267.

[7] M. FuJII, J. F. JIANG AND E. KAMEI, Characterization of chaotic order and its application to Furuta inequality, Proc. Amer. Math. Soc., 125 (1997), 3655-3658.

[8] M. FujII AND R. NAKAMOTO, Simultaneous extensions of Selberg inequality and Heinz-Kato-Furuta inequality, Nihonkai Math. J., 9 (1998), 219-225.

[9] C.-S. Lin, Heinz's inequality and Bernstein's inequality, Proc. Amer. Math. Soc., 125 (1997), 2319-2325.

[10] C.-S. Lin, Heinz-Kato-Furuta-type inequalities with bounds and equality conditions, Math. Inequal. Appl., 5 (2002), 735-743. 